\title{
RIP kinase-mediated ROS production triggers XAF1 expression through activation of TAp73 in casticin-treated bladder cancer cells
}

\author{
YOON HEE CHUNG ${ }^{1}$ and DAEJIN KIM ${ }^{2}$ \\ ${ }^{1}$ Department of Anatomy, Chung-Ang University College of Medicine, Seoul 06974; \\ ${ }^{2}$ Department of Anatomy, Inje University College of Medicine, Busan 47392, Republic of Korea
}

Received February 25, 2016; Accepted June 1, 2016

DOI: $10.3892 /$ or.2016.4895

\begin{abstract}
The p53 family protein p73 plays an important role in apoptosis induced by chemotherapeutic drugs. Transcriptionally active (TA) p73 (TAp73) substitutes for p53 in the response to stress. XIAP associated factor 1 (XAF1) is a novel predictive and prognostic factor in patients with bladder cancer, but the association between TAp73 and XAF1 expression in bladder cancer cells is poorly understood. Here, we investigated the status of TAp73 and XAF1 in T24 bladder cancer cells to identify molecular mechanisms in casticin-exposed T24 cells. Casticin induced activation of JNK/p38 MAPK that preceded activation of the caspase cascade and disruption of the mitochondria membrane potential $\left(\Delta \Psi_{\mathrm{m}}\right)$. Expression of XAF1 and TAp73 was also upregulated in casticin-treated T24 cells. Casticin treatment of T24 cells induced receptor-interacting protein (RIP) kinase expression and increased intracellular production of reactive oxygen species (ROS). Casticin-mediated ROS induced an increase in phosphorylated JNK/p38 MAPK, resulting in progressive upregulation of TAp73, which in turn led to XAF1 expression. Our data suggest that the apoptotic activity of casticin in T24 cells is mediated by activation of the TAp73-XAF1 signaling pathway through RIP kinase-mediated ROS production.
\end{abstract}

\section{Introduction}

Casticin prepared from the fruit of Vitex trifolia L. has a wide range of activities, including antitumor effects in a variety of cancers such as leukemia and uterine cervix, lung, and colon cancers (1-3). Casticin induces G2/M growth arrest and apoptosis in breast cancer cells regardless of p53 expression,

Correspondence to: Dr Daejin Kim, Department of Anatomy, Inje University College of Medicine, 75 Bokji-ro, Busanjin-gu, Busan 47392, Republic of Korea

E-mail: kimdj@inje.ac.kr

Key words: casticin, transcriptionally active p73, XIAP associated factor 1, RIP kinase, bladder cancer and Bcl-2 depletion is a key event in casticin-induced apoptosis (4). Casticin also triggers tumor necrosis factor-related apoptosis-inducing ligand (TRAIL)-induced apoptosis in human colon cancer cells through downregulation of Bcl-2 and X-linked inhibitor of apoptosis protein (XIAP) (3). Although wild-type p53 mediates increased sensitivity to radiation or chemotherapeutic agents (5), casticin induces apoptosis in human cervical cancer HeLa cells lacking wildtype p53 expression (6). Therefore, understanding the role of p53 or related proteins in casticin-treated human cancer cells is important for elucidation of the signaling pathway leading to apoptosis

The p53 family proteins, p53, p63, and p73, play important roles in development and tumorigenesis (7). The transcriptionally active (TA) isoforms of p63 and p73 can substitute for p53 in the context of inducing apoptosis or cell cycle arrest $(8,9)$.p73 is expressed as two major isoform classes, TAp73 and $\Delta \mathrm{Np} 73$ (N-terminal deleted form), which have distinct functions (10). Following induction of DNA damage by genotoxic drugs, TAp73 can bind to the same set of p53-responsive elements and activate downstream target genes of p53 to provoke the cell cycle arrest or induce apoptosis (11). The expression of XIAP-associated factor 1 (XAF1), as a novel target of p53, increases the activity of p53-dependent apoptosis (12). XAF1 as a tumor suppressor is also markedly reduced in muscleinvasive bladder tumors $(13,14)$. However, the relationship between XAF1 and TAp73 and the detailed mechanisms of XAF1 induction in bladder cancer are still not fully elucidated.

Intracellular production of reactive oxygen species (ROS) triggers apoptosis of EBV-infected human B cells through disruption of the mitochondria membrane potential resulting from upregulation of TAp73 and XAF1 (15). Casticin also induces apoptosis of cancer cells through the generation of ROS and activation of caspase-9 (6). Receptor-interacting protein (RIP) kinase family members have emerged as essential sensors of intracellular and extracellular stresses (16), and the interaction of phosphorylated RIP1 and RIP3 generates downstream ROS production to induce cell death (17). In this study, we examined the role and mechanism of ROS production in casticin-treated bladder cancer cells and investigated whether ROS-mediated TAp73 expression regulates the expression of XAF1 in bladder cancer after treatment with casticin. 


\section{Materials and methods}

Cell culture. The human bladder cell line T24 was purchased from the American Type Culture Collection (Manassas, VA, USA). Cells were maintained in RPMI-1640 medium (Hyclone, Logan, UT, USA) supplemented with 10\% FBS (Hyclone) and antibiotics under a humidified atmosphere with $5 \% \mathrm{CO}_{2}$.

Drug and chemicals. Casticin was purchased from Santa Cruz Biotechnology (Santa Cruz, CA, USA), dissolved in sterile dimethyl sulfoxide (DMSO) as a 200-mM stock solution, and diluted in medium to the indicated concentration before use. z-LEHD-fmk (z-Leu-Glu(OMe)-His-Asp-(OMe)-fluoremethylketone), z-DEVD-fmk (N-benzyloxycarbonyl-Asp-Glu-ValAsp-fluoromethylketone), z-VAD-fmk (N-benzyloxycarbonylIle-Glu-Thr-Asp-fluoromethyl ketone), SB203580, and SP600125 were purchased from Calbiochem (San Diego, CA, USA). N-acetylcysteine (NAC) was obtained from SigmaAldrich (St. Louis, MO, USA). Necrostatin-1 was purchased from Selleckchem (Houston, TX, USA).

Analysis of apoptotic cells by flow cytometry. The percentage of T24 cells undergoing apoptosis was determined by flow cytometry using FITC-labeled Annexin-V (BD Biosciences, San Diego, CA, USA) and 7-aminoactinomycin D (7-AAD) (BD Biosciences). To determine optimal conditions, experiments were performed using different concentrations of casticin $(0,10,20,50,100$ and $200 \mu \mathrm{M})$ and different periods of incubation $(2,4,8,24$ and $48 \mathrm{~h})$. DMSO $(0.05 \%)$ was used as a vehicle control. To examine the role of caspases, cells were pretreated with z-LEHD-fmk ( $20 \mu \mathrm{M}$, caspase-9 inhibitor), z-DEVD-fmk (20 $\mu \mathrm{M}$, caspase-3 inhibitor) or z-VAD-fmk (20 $\mu \mathrm{M}$, pan-caspase inhibitor) for $2 \mathrm{~h}$ before casticin treatment. Cells were harvested, rinsed with PBS, and resuspended in $100 \mu 1$ of $1 \mathrm{X}$ Annexin-V binding buffer [10 mM HEPES/ $\mathrm{NaOH}$ (pH 7.4), $140 \mathrm{mM} \mathrm{NaCl}, 2.5 \mathrm{mM} \mathrm{CaCl}_{2}$ ]. After addition of $3 \mu \mathrm{l}$ of Annexin-V-FITC and $3 \mu \mathrm{l}$ of 7-AAD the cells were incubated at room temperature for $15 \mathrm{~min}$ in the dark with gentle vortexing. Stained cells were analyzed using a FACSCalibur flow cytometer (BD Biosciences) equipped with CellQuestpro software (BD Biosciences).

Measurement of mitochondria membrane potential $\left(\Delta \Psi_{m}\right)$ and intracellular reactive oxygen species (ROS) production. Changes in mitochondrial membrane potential were measured using $\mathrm{DiOC}_{6}$ (3,3'-dihexyloxacarboxyanine iodide; Molecular Probes, Eugene, OR, USA). Cells were treated with casticin or DMSO for $24 \mathrm{~h}$, washed twice in PBS, resuspended in PBS supplemented with $\mathrm{DiOC}_{6}(20 \mathrm{nM})$, incubated at $37^{\circ} \mathrm{C}$ for $15 \mathrm{~min}$ in the dark, and immediately analyzed with a flow cytometer using the FL-1 filter.

Intracellular accumulation of ROS was monitored by flow cytometry after staining with the fluorescent probe DCFH-DA (10 $\mu \mathrm{M}, 2^{\prime}, 7^{\prime}$-dichlorodihydro-fluorescein diacetate; Molecular Probes) as previously described (15) with slight modification. DCFH-DA is deacetylated in cells by esterases to yield a nonfluorescent compound, DCFH, which remains trapped within the cell and is cleaved and oxidized by ROS in the presence of endogenous peroxidase to yield a highly fluorescent compound, DCF (2',7'-dichlorofluorescein). Cells were preincubated with
$10 \mu \mathrm{M}$ DCFH-DA for $30 \mathrm{~min}$ at $37^{\circ} \mathrm{C}$ and then seeded in 6-well plates $\left(5 \times 10^{5}\right.$ cells $\left./ \mathrm{ml}\right)$ and treated with or without casticin for $24 \mathrm{~h}$. Cells were washed, resuspended in PBS, and ROS levels were determined using a FACSCalibur flow cytometer.

Western blot analysis. Cells were washed in PBS and lysed in NP-40 buffer (Elpis Biotech, Daejeon, Korea) supplemented with a protease inhibitor cocktail (Sigma-Aldrich). To address phosphorylation events, an additional set of phosphatase inhibitors (Cocktail II, Sigma-Aldrich) was added to the NP-40 buffer. Protein concentration was determined using a BCA assay kit (Pierce, Rockford, IL, USA). Proteins (10 $\mu \mathrm{g} / \mathrm{sample})$ were resolved by SDS-PAGE and transferred to nitrocellulose (Millipore Corp., Billerica, MA, USA). The membranes were blocked with 5\% skim milk and western blot analysis was performed using a standard commercial method. Immunoreactivity was detected using an enhanced chemiluminescence (ECL) kit (Advansta Corp., Menlo Park, CA, USA) and Multiple Gel DOC system (Fujifilm). Primary antibodies (Abs) against the following proteins were used: caspase-8, caspase-3, caspase-9, PARP, $\beta$-actin, Bcl-2, Bax, Mcl-1, Bak, p53, XIAP, RIP, phospho-JNK ( $\mathrm{Thr}^{183} / \mathrm{Tyr}^{185}$ ), JNK, phospho-p38-MAPK ( $\left.\mathrm{Thr}^{180} / \mathrm{Tyr}^{182}\right)$, p38-MAPK, phospho-ERK1/2 $\left(\mathrm{Thr}^{202} / \mathrm{Tyr}^{204}\right)$, and ERK1/2 (Cell Signaling Technology, Beverly, MA, USA); XAF1 and TAp73 (Abcam, Cambridge, UK); TAp63 (BioLegend, San Diego, CA, USA).

Small interfering RNA (siRNA) transfection. Experimentally verified human TAp73-siRNA duplex and negative controlsiRNA were obtained from Bioneer (Daejeon, Korea). Cells were transiently transfected under optimized conditions. Briefly, cells were seeded at a concentration of $1 \times 10^{5}$ cells per well in a 6-well plate and grown overnight. Cells in each well were transfected with $200 \mathrm{nM}$ siRNA using Lipofectamine RNAiMAX Reagent (Invitrogen, Carlsbad, CA, USA) according to the manufacturer's instructions. Cells were used for further experiments $48 \mathrm{~h}$ after transfection.

Statistical analysis. Data were expressed as mean \pm standard deviation (SD). Statistical analysis was conducted using one-way analysis of the variance (ANOVA). P-values $<0.05$ were considered statistically significant.

\section{Results}

Casticin induces apoptosis of bladder cancer cells in a timeand dose-dependent manner. To evaluate whether casticin affects cell survival through regulation of the mitochondria membrane potential, the percentage of apoptotic cells in casticin-treated T24 cells was determined by flow cytometry using FITC-labeled Annexin-V and 7-AAD and the mitochondria membrane potential was measured by staining with $\mathrm{DiOC}_{6}$. Casticin treatment of $\mathrm{T} 24$ cells resulted in a dose- and time-dependent increase in the Annexin- $\mathrm{V}^{+} / 7-\mathrm{AAD}^{+}$population (Fig. 1A and B). Casticin also significantly disrupted the integrity of the mitochondria membrane after $8 \mathrm{~h}$ of treatment (Fig. 1A and B). We further analyzed the activity of caspases by immunoblotting. Levels of cleaved forms of caspase- 8 , caspase- 9 and caspase- 3 were increased in T24 cells after treatment with casticin. Cleavage of PARP was also 

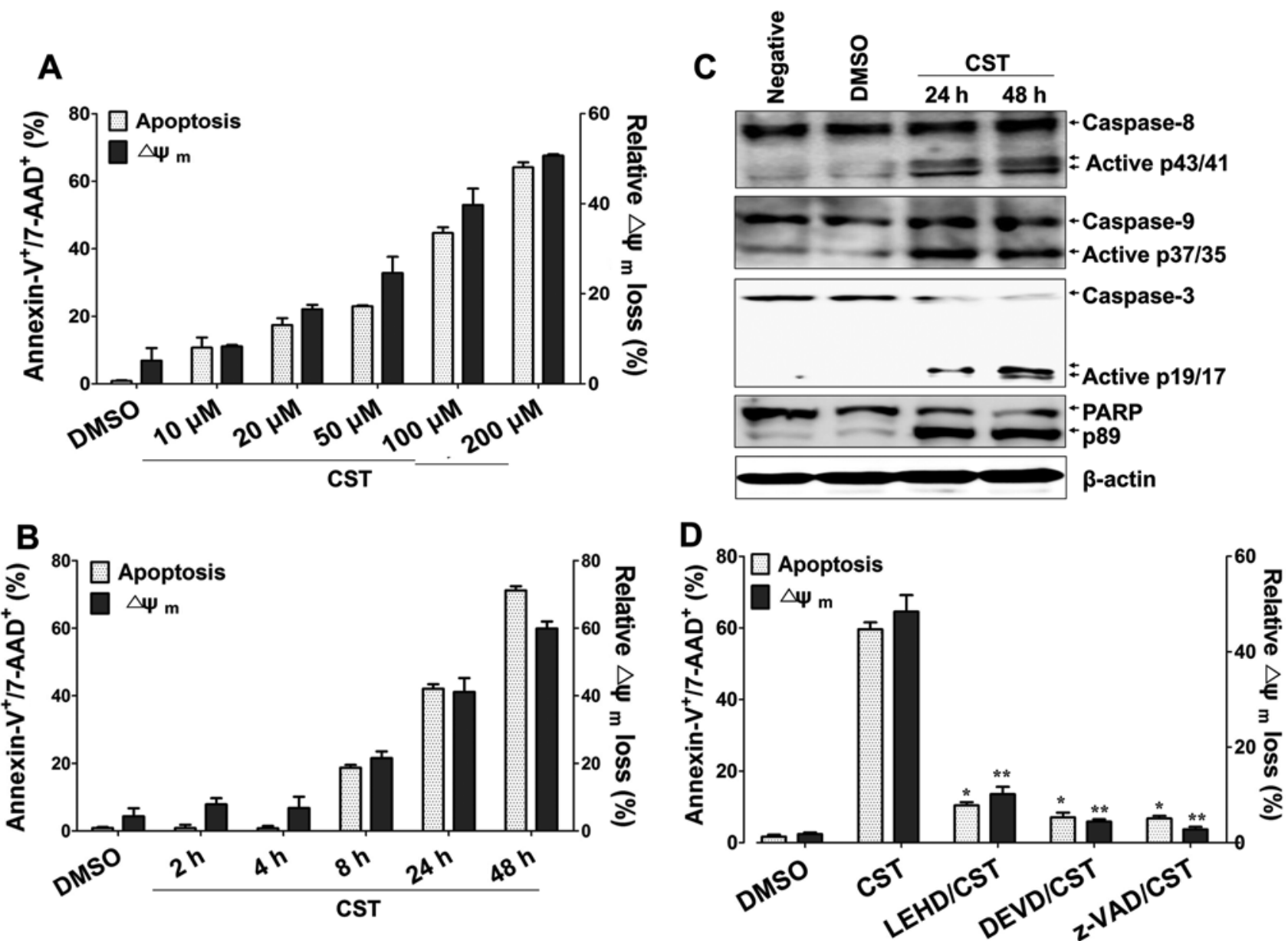

Figure 1. Casticin (CST) induces caspase-mediated apoptosis in human bladder cancer cells. (A) Cells were treated with 10, 20, 50, 100 or 200 $\mu \mathrm{M}$ casticin for $24 \mathrm{~h}$. (B) Cells were treated with $100 \mu \mathrm{M}$ casticin for 2, 4, 8, 24 or $48 \mathrm{~h}$. (C) Cells were treated with $100 \mu \mathrm{M}$ casticin for the indicated times. (D) Cells were preincubated with z-LEHD-fmk $(20 \mu \mathrm{M})$, z-DEVD-fmk $(20 \mu \mathrm{M})$ or z-VAD-fmk $(20 \mu \mathrm{M})$ for $2 \mathrm{~h}$ and then treated with $100 \mu \mathrm{M}$ casticin for $24 \mathrm{~h}$. Western blot analysis of active casapse- $8,-9$ and -3 or PARP cleavage was performed to characterize the apoptotic response. $\beta$-actin was used to normalize protein content To detect the degree of apoptosis, cells were stained with Annexin-V-FITC and 7-AAD and analyzed by flow cytometry. The percentage of apoptotic cells was determined by the proportion of Annexin- $\mathrm{V}^{+} / 7-\mathrm{AAD}^{+}$cells. To measure disruption of $\Delta \Psi_{\mathrm{m}}$, cells were stained with DiOC 6 . Diminished DiOC 6 fluorescence $(\%)$ indicates $\Delta \Psi_{\mathrm{m}}$ disruption. Each value represents the mean $\pm \mathrm{SD}$ of three determinations. ${ }^{*} \mathrm{p}<0.01$ (apoptosis of T24 treated with casticin versus T24 treated with inhibitor and casticin); ${ }^{* *} \mathrm{p}<0.01\left(\Delta \Psi_{\mathrm{m}}\right.$ of T24 treated with casticin versus $\mathrm{T} 24$ treated with inhibitor and casticin).

detected in the presence of casticin (Fig. 1C). Treatment with specific caspase inhibitors z-LEHD-fmk (caspase-9 inhibitor) or z-DEVD-fmk (caspase-3 inhibitor) or the pan-caspases inhibitor z-VAD, effectively blocked casticin-mediated apoptosis (Fig. 1D). These results suggest that casticin-induced apoptosis of bladder cancer cells involves interruption of the mitochondria membrane potential and activation of caspases.

MAPK-mediated expression of TAp73 and XAF1 regulates casticin-induced apoptosis. On the basis of previous results we investigated the expression of XAF1, apoptosis-related proteins, and p53 family proteins to elucidate the underlying mechanism of casticin-induced T24 cell apoptosis. Although casticin treatment had no influence on the expression level of p53 and induction of TAp63, the level of TAp73 was markedly elevated in casticin-exposed T24 cells. XAF1 expression was also upregulated, whereas XIAP was downregulated (Fig. 2A). The levels of antiapoptotic proteins, including Mcl-2 and $\mathrm{Bcl}-2$, were decreased, whereas expression of proapoptotic proteins (Bak and Bax) was increased (Fig. 2B). Because
JNK and p38 MAPK regulate phosphorylation and activation of TAp73 $(18,19)$, we next examined whether activation of mitogen-activated protein kinases (MAPKs) is correlated with the induction of TAp73 in casticin-treated T24 cells. Casticin significantly induced the phosphorylation of JNK and p38 MAPK, whereas activation of ERK was blocked (Fig. 2C). Pharmacological inhibition of JNK and p38 with SP600125 and SB203580, respectively, not only suppressed the activation of caspase-9 and caspase-3 (Fig. 2D), but also attenuated the casticin-induced expression of XAF1, TAp73, Bak and Bax (Fig. 2E and F). These results suggest that MAPKs are involved in the upregulation of XAF1 and TAp73 in T24 cells after treatment with casticin.

ROS-modulated TAp73 controls XAF1 expression and activation of caspases after treatment with casticin. We next investigated whether the apoptotic effect of XAF1 is regulated by the expression and activation of TAp73 in casticin-exposed T24 cells. To define the relationship between TAp73 activation and induction of XAF1, we analyzed the expression of 
A

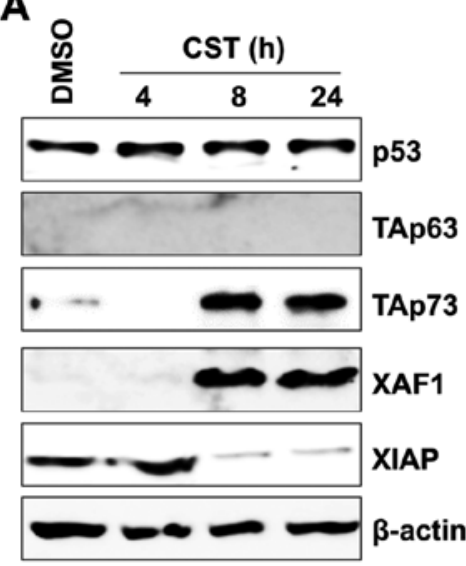

C

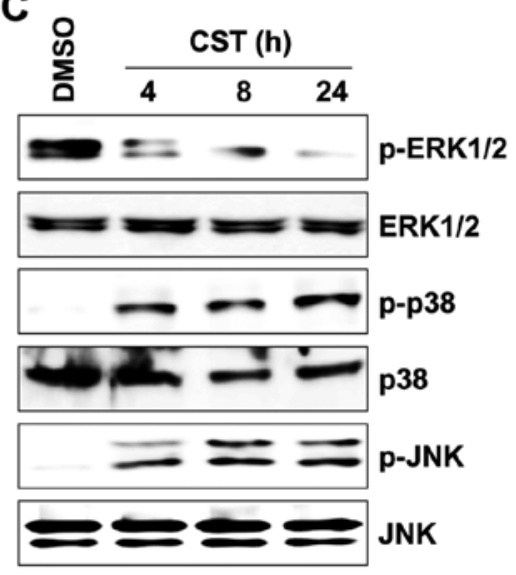

E

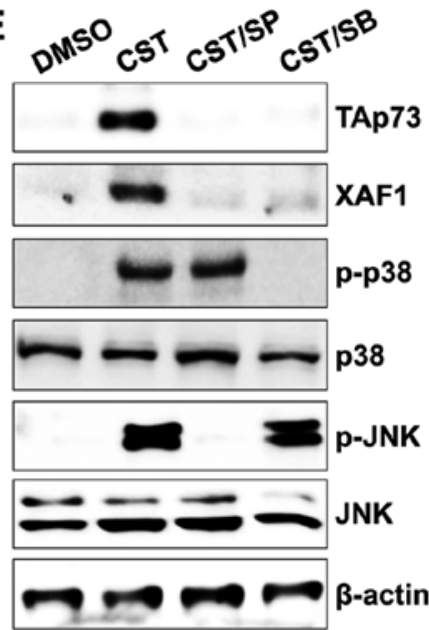




Figure 2. The role of JNK and p38-MAPK in TAp73 expression in human bladder cancer cells after casticin (CST) treatment. Cells were treated with $100 \mu \mathrm{M}$ casticin for the indicated times. Total proteins were extracted from cell lysates and western blot analysis was performed for (A) p53, TAp63, TAp73, XAF1 or XIAP protein (B) and Bax, Bcl-2, Mcl-1 or Bak protein. (C) Total cell lysates were immunoblotted with antibody against p-ERK, ERK, p-JNK, JNK, p-p38-MAPK, and p38-MAPK. (D and E) Cells were pretreated with $25 \mu \mathrm{M}$ SP600125 (SP) or $10 \mu \mathrm{M}$ SB203580 (SB) for $1 \mathrm{~h}$. Cells were then washed with PBS and treated with $100 \mu \mathrm{M}$ casticin for $24 \mathrm{~h}$. Total cell lysates were immunoblotted with antibody against (D) caspase-9, caspase-3 or PARP, (E) XAF1, TAp73, p-p38-MAPK, MAPK, p-JNK or JNK, and (F) Bak, Bax, Bcl-2 or Mcl-1. $\beta$-actin was used to normalize protein content. Results are representative of three independent experiments.

XAF1 and activation of MAPKs in casticin-treated T24 cells after silencing TAp73 with siRNA. Knockdown of TAp73 with siRNA resulted in downregulation of XAF1 but had no effect on the activation of JNK and p38 MAPK (Fig. 3A). Gene silencing of TAp73 effectively blocked the cleavage of caspase-9, caspase-3, and PARP in casticin-treated T24 cells (Fig. 3B). In addition, the level of proapoptotic proteins (Bak and Bax) was suppressed in TAp73-knockdown T24 cells after treatment with casticin (Fig. 3C). As ROS production is an early signal mediator for apoptosis induction after treatment with casticin $(3,6,20)$ we examined the effect of ROS on XAF1 and TAp73 activation in casticin-treated T24 cells. Casticin upregulated intracellular ROS levels within $1 \mathrm{~h}$ (Fig. 4A). Moreover, NAC (a ROS scavenger) not only efficiently inhibited ROS production (Fig. 4B), but also blocked generation of the cleaved forms of caspase-9, caspase-3, and PARP (Fig. 4C). Furthermore, expression of XAF1, TAp73, phosphorylated p38, and phosphorylated JNK was suppressed by NAC treatment (Fig. 4D). These results suggest that ROS-mediated TAp73 expression is one of the critical factors for activation of XAF1 and induction of apoptosis in casticin-treated T24 cells.
RIP-mediated ROS generation initiates the TAp73/XAFI apoptosis pathway in casticin-treated T24 cells. RIP kinases mediate apoptosis or necrosis induced by tumor necrosis factor (TNF)- $\alpha$ or genotoxic stresses through the accumulation of $\operatorname{ROS}(21,22)$. ROS are also closely associated with the caspase cascade and activation of MAPKs (23). Our previous results showed that casticin promoted ROS-induced MAPK phosphorylation to activate caspases and induce apoptosis of T24 cells. Therefore, we examined whether RIP kinases are involved in ROS production for activation of the TAp73/XAF1 signaling pathway in casticin-treated T24 cells. Casticin elicited RIP kinase expression (Fig. 5A). Treatment with necrostatin-1 (a RIP kinase inhibitor) blocked the cleavage of caspases (Fig. 5B), attenuated ROS generation (Fig. 5C), and suppressed MAPK-mediated TAp73/XAF1 activation (Fig. 5D) in T24 cells after treatment with casticin. However, gene silencing of TAp73 with siRNA and treatment with MAPK inhibitors (SP600125 and SB203580) failed to block the expression of RIP kinase in casticin-treated T24 cells (Fig. 5E and F). In addition, NAC treatment of casticin-exposed T24 cells had no influence on the activation of RIP kinase (Fig. 5G). These 



Figure 3. Casticin (CST)-induced TAp73 is involved in XAF1 expression and mitochondrial events. Cells were treated with $100 \mu \mathrm{M}$ casticin for $6 \mathrm{~h}$ and then transfected with $200 \mathrm{nM}$ si-TAp73. Cells were used for further experiments $36 \mathrm{~h}$ after transfection. Whole cell lysates were subjected to western blot analysis using antibodies against (A) XAF1, TAp73, p-p38-MAPK, MAPK, p-JNK or JNK, (B) caspase-9, -3 or PARP, and (C) Bcl-2, Bax, Bak or Mcl-1. $\beta$-actin was used to normalize protein content. Results are representative of three independent experiments.
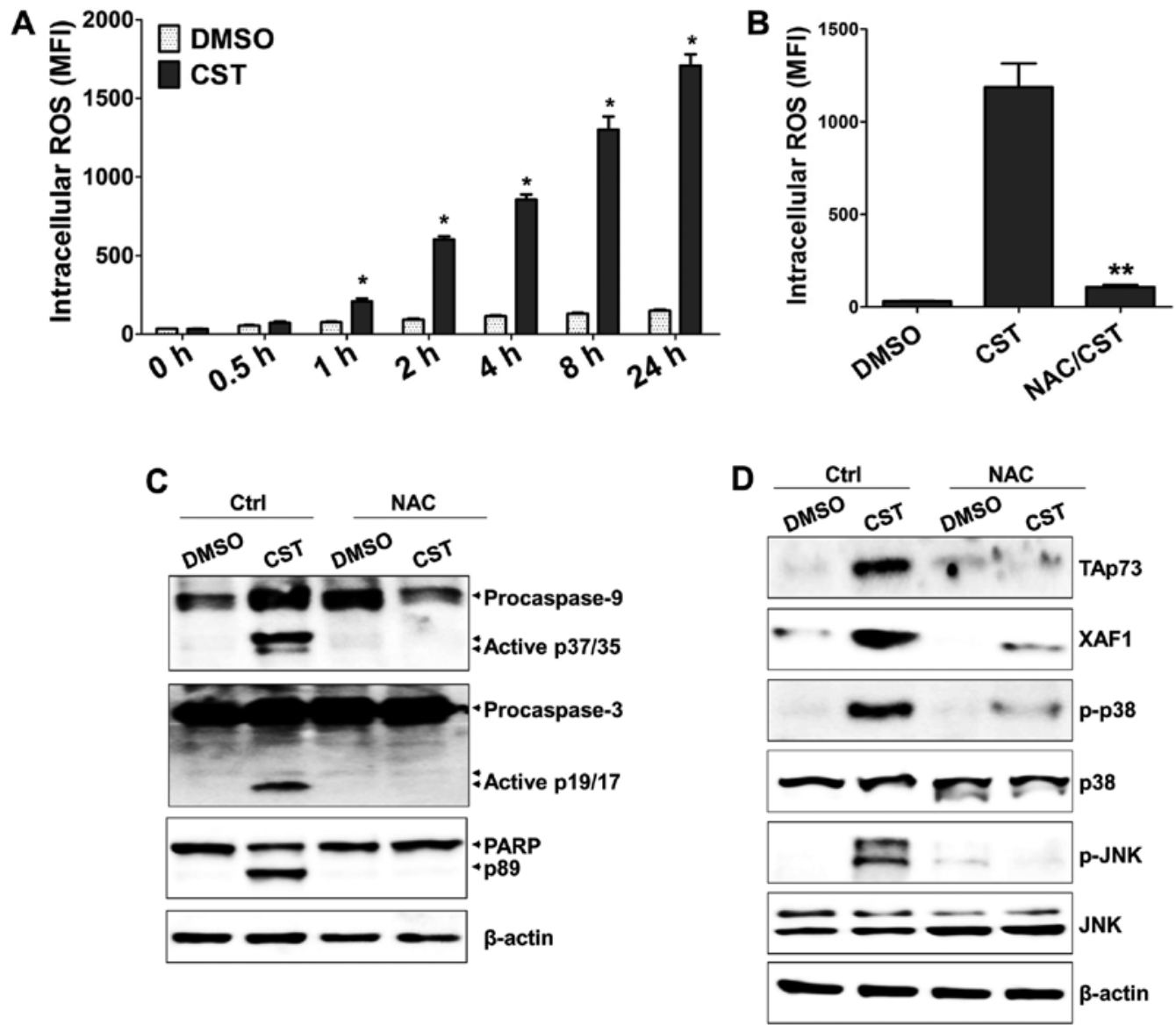

Figure 4. Casticin (CST) induces an increase in intracellular ROS production and the ROS scavenger N-acetylcysteine (NAC) blocks casticin-induced TAp73/ XAF1 expression and JNK/p38-MAPK activation in human bladder cancer cells. (A) Cells were pretreated with $10 \mu \mathrm{M}$ DCFH-DA for 30 min and then treated with $100 \mu \mathrm{M}$ casticin or DMSO at $37^{\circ} \mathrm{C}$ for the indicated times. The numbers in histograms indicate the mean fluorescence intensity (MFI) for DCFH-DA. (B-D) Cells were pretreated with $10 \mathrm{mM} \mathrm{NAC}$ for $1 \mathrm{~h}$ to block ROS production, washed with PBS, and treated with $100 \mu \mathrm{M}$ casticin or DMSO for $24 \mathrm{~h}$. (B) Effect of NAC on casticin-induced ROS production was measured using flow cytometry. The numbers in histograms indicate the mean fluorescence intensity (MFI) for DCFH-DA. Whole cell lysates were subjected to western blot analysis using antibodies against (C) caspase-9, -3 or PARP, and (D) XAF1, TAp73, p-p38-MAPK, MAPK, p-JNK or JNK. $\beta$-actin was used to normalize protein content. Results are representative of three independent experiments. ${ }^{*} \mathrm{p}<0.01$ (ROS production of T24 treated with DMSO (control) versus T24 treated with casticin); ${ }^{* *} \mathrm{p}<0.01$ (ROS production of T24 treated with casticin versus T24 treated with NAC and casticin). 

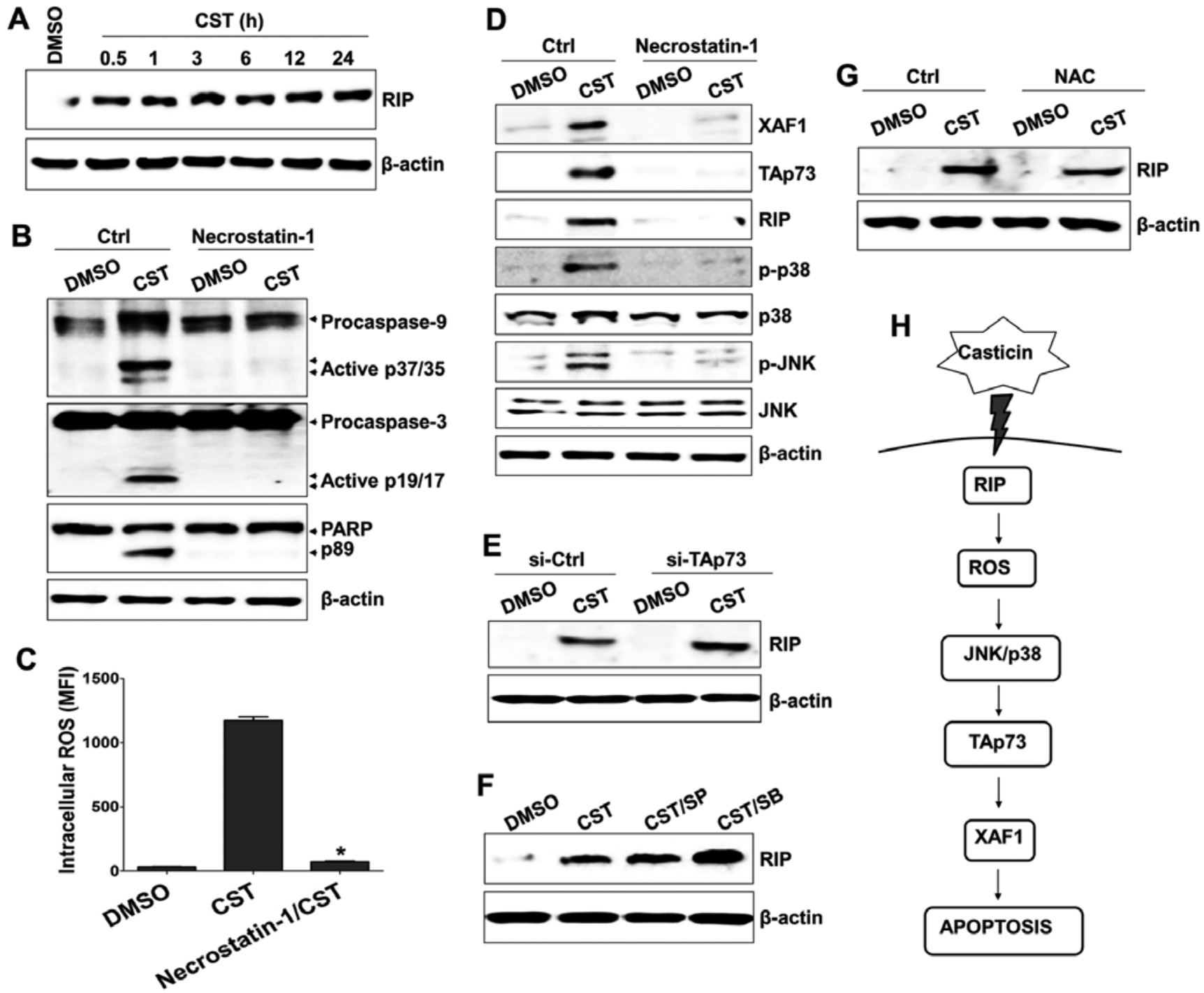

Figure 5. Receptor-interacting protein (RIP) is an upstream signaling molecule in casticin (CST)-induced ROS generation and TAp73 expression. (A) Cells were treated with $100 \mu \mathrm{M}$ casticin for the indicated times. Total proteins were extracted from cell lysates and subjected to western blotting for RIP. (B-D) Cells were pretreated with $30 \mu \mathrm{M}$ necrostatin-1 for $1 \mathrm{~h}$ to block RIP expression and then treated with $100 \mu \mathrm{M}$ casticin or DMSO at $37^{\circ} \mathrm{C}$ for $24 \mathrm{~h}$. (B) Whole cell lysates were subjected to western blot analysis using antibodies to caspase-9, -3 or PARP. (C) Effects of necrostatin-1 on casticin-induced ROS production was measured using flow cytometry. The numbers in histograms indicate the mean fluorescence intensity (MFI) for DCFH-DA. " $\mathrm{p}<0.01$ (ROS production of T24 treated with casticin versus T24 treated with necrostatin-1 and casticin). (D) Whole cell lysates were subjected to western blot analysis using antibodies against RIP, XAF1, TAp73, p-p38-MAPK, MAPK, p-JNK or JNK. (E) Cells were treated with $100 \mu \mathrm{M}$ casticin for $6 \mathrm{~h}$ and then transfected with $200 \mathrm{nM}$ si-TAp73. Cells were used for further experiments $48 \mathrm{~h}$ after transfection. Whole cell lysates were subjected to western blot analysis of RIP. (F) Cells were pretreated with $25 \mu \mathrm{M}$ SP600125 (SP) or $10 \mu \mathrm{M} \mathrm{SB} 203580$ (SB) for $1 \mathrm{~h}$, washed with PBS, and treated with $100 \mu \mathrm{M}$ casticin for $24 \mathrm{~h}$. Total cell lysates were immunoblotted with antibody against RIP. (G) Cells were pretreated with $10 \mathrm{mM} \mathrm{N}$-acetylcysteine for $1 \mathrm{~h}$, washed with PBS, and treated with $100 \mu \mathrm{M}$ casticin for $24 \mathrm{~h}$. Total cell lysates were immunoblotted with antibody against RIP. $\beta$-actin was used to normalize protein content. (H) Schematic diagram of the intracellular signaling mechanism during casticin-induced apoptosis in human bladder cancer cells.

results suggest that the activation of RIP kinase plays a critical role in casticin-induced apoptosis through ROS production.

\section{Discussion}

Wild-type p53 functions as a cancer suppressor by increasing the sensitivity of cells to radiation or chemotherapeutic agents (5); however, casticin induces apoptotic cell death in p53 mutant or null breast and cervical cancer cells $(1,4)$. Previous studies have shown that casticin enhances TRAIL-induced apoptosis and suppresses cell survival proteins, including Bcl-2 and XIAP (3). Melphalan, a therapeutic agent for multiple myeloma, promotes TAp73-mediated XAF1 expression via
ROS generation and activates the p38 MAPK pathway to induce apoptosis (15). Based on these results, we investigated whether casticin potentiates the ROS-mediated apoptosis pathway in a p53-independent manner. We also examined the underlying mechanism of XAF1 activation and the relationship between TAp73 and XAF in casticin-treated T24 cells.

The $X A F 1$ gene, which is located at $17 \mathrm{p} 13.2$, was first identified as a novel negative regulator of XIAP (24). XAF1 binds to XIAP and antagonizes its ability to mediate apoptosis through activation of the caspase cascade in cancer cells (25). XAF1 levels are significantly lower in cancer tissues than in normal tissues (26); however, XAF1 expression is significantly increased in colorectal cancer cells after treatment with cisplatin 
(27). A reduction in XAF1 expression was reported in 50\% (10 of 20) of transitional cell carcinomas and 60\% (12 of 20) of renal cell carcinomas (14). In addition, this reduction of XAF1 was significantly greater in invasive and high-grade tumors (14). Because XAF1 expression is involved in activation of p53 and expression of its downstream target genes (14) it is essential to understand the changes in p53 family proteins, including p63 and p73. As a proapoptotic protein, XAF1 promotes the translocation of Bax to the mitochondria and the release of cytochrome $c$ from mitochondria to trigger apoptosis (28). In this study, we showed that casticin induced apoptosis of T24 bladder cancer cells through activation of caspases and disruption of the mitochondria membrane potential. ROS-mediated MAPK activation triggered expression of TAp73 and activation of XAF1 in casticin-treated T24 cells (Fig. 5H). Loss of TAp73 expression led to downregulation of XAF1 and suppression of casticin-induced apoptosis. These results suggest that the TAp73/XAF1 signaling pathway is a new therapeutic target for modulating carcinogenesis in the bladder.

The TAp73 protein, which is activated by Ras, controls the expression of glucose-6-phosphate dehydrogenase for glucose metabolism in bladder cancer cells (29). In addition to its role in tumor suppression and promotion, p73 is required for neuronal differentiation and development of the central nervous system (8). TAp73-knockdown mammary epithelial cells lose their epithelial characteristics and express mesenchymal markers, including Snail-1, Slug, and Twist (30). The expression of fibroblast growth factor receptor 3 (FGFR3), a transcriptional target of TAp73, is closely related to the transition of superficial bladder cancers to an invasive phenotype (31). These results suggest that TAp73 is not only a key regulatory molecule in the control of cancer cell survival and carcinogenesis but also an alternative target for blocking metastasis in bladder cancer.

In addition to their role in inflammation and other immune responses, RIP kinases also have an important function in death-inducing processes (32). RIP1 binds to several death receptors, such as the death domain of receptor Fas (CD95), TNF receptor 1 (TNF-R1), TRAIL receptor 1 (TRAIL-R1), and TRAIL-R2 $(33,34)$. RIP3 can interact with phosphorylated RIP1 upon TNF stimulation, leading to the generation of necrosomes and cell death (17). RIP1 plays an important role in TNF-R1-mediated NF- $\mathrm{B}$ activation for cell survival $(35,36)$. In contrast, casticin enhances the TRAIL-induced death of colon cancer cells (3). In this study we showed that casticin-treated bladder cancer cells produce ROS through the activation of RIP kinase and thereby initiate the apoptosis signaling pathway. Although necrostatin-1 (an inhibitor of RIP kinase) blocked the entire apoptotic process of casticin-treated T24 cells, treatment with MAPK inhibitors or gene silencing of TAp73 with siRNA failed to suppress the activation of RIP kinase after treatment with casticin. These results suggest that ROS generation induced by RIP kinase activation is a critical upstream event in casticin-induced apoptosis in T24 bladder cancer cells.

Urothelial carcinoma is the fifth most common cancer in developed countries (37). XAF1 levels in bladder cancer cells are significantly decreased compared with those in normal cells (14). Casticin has previously been shown to exert antitumor activity by activating proapoptotic pathways in various cancers (22). The results of this study implicate casticin as a new candidate therapeutic drug for the control of bladder cancer through enhancement of the TAp73-induced XAF1 apoptosis signaling pathway.

\section{Acknowledgements}

This study was supported by the Basic Science Research Program through the National Research Foundation of Korea (NRF) funded by the Ministry of Education, Science and Technology (NRF-2015R1D1A1A01056672).

\section{References}

1. Csupor-Löffler B, Hajdú Z, Zupkó I, Réthy B, Falkay G, Forgo P and Hohmann J: Antiproliferative effect of flavonoids and sesquiterpenoids from Achillea millefolium s.l. on cultured human tumour cell lines. Phytother Res 23: 672-676, 2009.

2. Shen JK, Du HP, Yang M, Wang YG and Jin J: Casticin induces leukemic cell death through apoptosis and mitotic catastrophe. Ann Hematol 88: 743-752, 2009.

3. Tang SY, Zhong MZ, Yuan GJ, Hou SP, Yin LL, Jiang H and Yu ZY: Casticin, a flavonoid, potentiates TRAIL-induced apoptosis through modulation of anti-apoptotic proteins and death receptor 5 in colon cancer cells. Oncol Rep 29: 474-480, 2013.

4. Haïdara K, Zamir L, Shi QW and Batist G: The flavonoid Casticin has multiple mechanisms of tumor cytotoxicity action. Cancer Lett 242: 180-190, 2006.

5. Pirollo KF, Bouker KB and Chang EH: Does p53 status influence tumor response to anticancer therapies? Anticancer Drugs 11: 419-432, 2000.

6. Chen D, Cao J, Tian L, Liu F and Sheng X: Induction of apoptosis by casticin in cervical cancer cells through reactive oxygen species-mediated mitochondrial signaling pathways. Oncol Rep 26: 1287-1294, 2011

7. Deyoung MP and Ellisen LW: p63 and p73 in human cancer: Defining the network. Oncogene 26: 5169-5183, 2007.

8. Yang A, Walker N, Bronson R, Kaghad M, Oosterwegel M, Bonnin J, Vagner C, Bonnet H, Dikkes P, Sharpe A, et al: p73-deficient mice have neurological, pheromonal and inflammatory defects but lack spontaneous tumours. Nature 404: 99-103, 2000.

9. Melino G, De Laurenzi V and Vousden KH: p73: Friend or foe in tumorigenesis. Nat Rev Cancer 2: 605-615, 2002.

10. Dötsch V, Bernassola F, Coutandin D, Candi E and Melino G: p63 and p73, the ancestors of p53. Cold Spring Harb Perspect Biol 2: a004887, 2010.

11. Jost CA, Marin MC and Kaelin WG Jr: p73 is a simian [correction of human] p53-related protein that can induce apoptosis. Nature 389: 191-194, 1997.

12. Zou B, Chim CS, Pang R, Zeng H, Dai Y, Zhang R, Lam CS, Tan VP, Hung IF, Lan HY, et al: XIAP-associated factor 1 (XAF1), a novel target of $\mathrm{p} 53$, enhances $\mathrm{p} 53$-mediated apoptosis via post-translational modification. Mol Carcinog 51: 422-432, 2012.

13. Liston P, Fong WG, Kelly NL, Toji S, Miyazaki T, Conte D, Tamai K, Craig CG, McBurney MW and Korneluk RG: Identification of XAF1 as an antagonist of XIAP anti-Caspase activity. Nat Cell Biol 3: 128-133, 2001.

14. Lee MG, Huh JS, Chung SK, Lee JH, Byun DS, Ryu BK, Kang MJ, Chae KS, Lee SJ, Lee CH, et al: Promoter CpG hypermethylation and downregulation of XAF1 expression in human urogenital malignancies: Implication for attenuated p 53 response to apoptotic stresses. Oncogene 25: 5807-5822, 2006.

15. Park GB, Kim YS, Kim D, Kim S, Lee HK, Cho DH, Lee WJ and Hur DY: Melphalan-induced apoptosis of EBV-transformed $B$ cells through upregulation of TAp73 and XAF1 and nuclear import of XPA. J Immunol 191: 6281-6291, 2013.

16. Declercq W, Vanden Berghe T and Vandenabeele P: RIP kinases at the crossroads of cell death and survival. Cell 138: 229-232, 2009.

17. Cho YS, Challa S, Moquin D, Genga R, Ray TD, Guildford M and Chan FK: Phosphorylation-driven assembly of the RIP1-RIP3 complex regulates programmed necrosis and virus-induced inflammation. Cell 137: 1112-1123, 2009. 
18. Wang P, Yu W, Hu Z, Jia L, Iyer VR, Sanders BG and Kline K Involvement of JNK/p73/NOXA in vitamin E analog-induced apoptosis of human breast cancer cells. Mol Carcinog 47: 436-445, 2008

19. Sanchez-Prieto R, Sanchez-Arevalo VJ, Servitja JM and Gutkind JS: Regulation of p73 by c-Abl through the p38 MAP kinase pathway. Oncogene 21: 974-979, 2002.

20. Yang J, Yang Y, Tian L, Sheng XF, Liu F and Cao JG: Casticininduced apoptosis involves death receptor 5 upregulation in hepatocellular carcinoma cells. World J Gastroenterol 17: 4298-4307, 2011.

21. Lin Y, Choksi S, Shen HM, Yang QF, Hur GM, Kim YS, Tran JH, Nedospasov SA and Liu ZG: Tumor necrosis factor-induced nonapoptotic cell death requires receptor-interacting proteinmediated cellular reactive oxygen species accumulation. J Biol Chem 279: 10822-10828, 2004.

22. Kaiser WJ and Offermann MK: Apoptosis induced by the toll-like receptor adaptor TRIF is dependent on its receptor interacting protein homotypic interaction motif. J Immunol 174: 4942-4952, 2005.

23. Müller M, Schilling T, Sayan AE, Kairat A, Lorenz K, SchulzeBergkamen H, Oren M, Koch A, Tannapfel A, Stremmel W, et al: TAp73/Delta Np73 influences apoptotic response, chemosensitivity and prognosis in hepatocellular carcinoma. Cell Death Differ 12: 1564-1577, 2005.

24. Liston P, Roy N, Tamai K, Lefebvre C, Baird S, ChertonHorvat G, Farahani R, McLean M, Ikeda JE, MacKenzie A, et al: Suppression of apoptosis in mammalian cells by NAIP and a related family of IAP genes. Nature 379: 349-353, 1996.

25. Arora V, Cheung HH, Plenchette S, Micali OC, Liston $P$ and Korneluk RG: Degradation of survivin by the X-linked inhibitor of apoptosis (XIAP)-XAF1 complex. J Biol Chem 282: 26202-26209, 2007.

26. Fong WG, Liston P, Rajcan-Separovic E, St Jean M, Craig C and Korneluk RG: Expression and genetic analysis of XIAPassociated factor 1 (XAF1) in cancer cell lines. Genomics 70: $113-122,2000$

27. Ju WC, Huang GB, Luo XY, Ren WH, Zheng DQ, Chen PJ, Lou YF and Li B: X-linked inhibitor of apoptosis-associated factor 1 (XAFl) enhances the sensitivity of colorectal cancer cells to cisplatin. Med Oncol 31: 273, 2014.
28. Straszewski-Chavez SL, Visintin IP, Karassina N, Los G, Liston P, Halaban R, Fadiel A and Mor G: XAF1 mediates tumor necrosis factor-alpha-induced apoptosis and X-linked inhibitor of apoptosis cleavage by acting through the mitochondrial pathway. J Biol Chem 282: 13059-13072, 2007.

29. Wang X, Wu G, Cao G, Yang L, Xu H, Huang J and Hou J: Zoledronic acid inhibits the pentose phosphate pathway through attenuating the Ras-TAp73-G6PD axis in bladder cancer cells. Mol Med Rep 12: 4620-4625, 2015.

30. Zhang Y, Yan W, Jung YS and Chen X: Mammary epithelial cell polarity is regulated differentially by $\mathrm{p} 73$ isoforms via epithelial-to-mesenchymal transition. J Biol Chem 287: 17746-17753, 2012.

31. Sayan AE, D'Angelo B, Sayan BS, Tucci P, Cimini A, Cerù MP, Knight RA and Melino G: p73 and p63 regulate the expression of fibroblast growth factor receptor 3. Biochem Biophys Res Commun 394: 824-828, 2010.

32. Zhang D, Lin J and Han J: Receptor-interacting protein (RIP) kinase family. Cell Mol Immunol 7: 243-249, 2010.

33. Stanger BZ, Leder P, Lee TH, Kim E and Seed B: RIP: A novel protein containing a death domain that interacts with Fas/APO-1 (CD95) in yeast and causes cell death. Cell 81: 513-523, 1995.

34. Chaudhary PM, Eby M, Jasmin A, Bookwalter A, Murray J and Hood L: Death receptor 5, a new member of the TNFR family, and DR4 induce FADD-dependent apoptosis and activate the NF-kappaB pathway. Immunity 7: 821-830, 1997.

35. Festjens N, Vanden Berghe T, Cornelis S and Vandenabeele P: RIP1, a kinase on the crossroads of a cell's decision to live or die. Cell Death Differ 14: 400-410, 2007.

36. Lin Y, Devin A, Cook A, Keane MM, Kelliher M, Lipkowitz S and Liu ZG: The death domain kinase RIP is essential for TRAIL (Apo2L)-induced activation of IkappaB kinase and c-Jun N-terminal kinase. Mol Cell Biol 20: 6638-6645, 2000.

37. Siegel R, Naishadham D and Jemal A: Cancer statistics, 2013. CA Cancer J Clin 63: 11-30, 2013. 